University of Nebraska - Lincoln

DigitalCommons@University of Nebraska - Lincoln

\title{
A comparison of pollen counts: Light versus scanning electron microscopy
}

Gretchen D. Jones

United States Department of Agriculture (USDA), g-jones@tamu.edu

Vaughn M. Bryant Jr.

Texas A \& M University

Follow this and additional works at: https://digitalcommons.unl.edu/usdaarsfacpub

Part of the Agricultural Science Commons

Jones, Gretchen D. and Bryant, Vaughn M. Jr., "A comparison of pollen counts: Light versus scanning electron microscopy" (2007). Publications from USDA-ARS / UNL Faculty. 542.

https://digitalcommons.unl.edu/usdaarsfacpub/542

This Article is brought to you for free and open access by the U.S. Department of Agriculture: Agricultural Research Service, Lincoln, Nebraska at DigitalCommons@University of Nebraska - Lincoln. It has been accepted for inclusion in Publications from USDA-ARS / UNL Faculty by an authorized administrator of DigitalCommons@University of Nebraska - Lincoln. 


\title{
A comparison of pollen counts: Light versus scanning electron microscopy
}

\author{
GRETCHEN D. JONES ${ }^{1} \&$ VAUGHN M. BRYANT, JR. ${ }^{2}$ \\ ${ }^{1}$ Areawide Pest Management Research Unit (APRMU), Agricultural Research Service (ARS), United States Department of \\ Agriculture (USDA), College Station, Texas, USA, ${ }^{2}$ Palynology Laboratory, Department of Anthropology, Texas A $\& M$ \\ University (TAMU), College Station, Texas, USA
}

\begin{abstract}
Palynologists use compound light microscopy (LM) for pollen identification and interpretation and scanning electron microscopy (SEM) for morphological comparisons and taxonomy. As we are unaware of any published reports comparing LM and SEM pollen counts and identifications of the same sample, we decided to examine a surface soil sample using both microscopes. Standard palynological extraction techniques were used. Two, 300 grain counts were made using LM, and two, 300 counts with SEM. Pollen grains viewed with SEM were also divided into three categories, "identifiable," "obscured," and "virtually impossible to identify". Eighty-six (86) percent of the pollen grains counted with SEM were classified as "identifiable" or "obscured." Pollen concentration values ranged from 385,714 (LM Count \#2) to 900,000 (SEM Count \#1) per gram of soil. Regardless of the microscope used, Ligustrum spp., Myrtaceae-type, and Tilia spp. had the greatest number of pollen grains. A total of 73 taxa were found. A scan of the unexamined portion of the stubs resulted in 20 additional taxa. There were no significant differences between the counts made with the two microscopes (ANOVA, $\mathrm{p}>0.05, \mathrm{~F}=0.18, \mathrm{df}=76)$. However, there were significantly more taxa found with SEM than with $\mathrm{LM}(\mathrm{t}$-test, $\mathrm{T}=0.05)$. Sample preparation and the time needed to count, analyze, photograph and print the micrographs are the same regardless of the microscope used. The sample, information needed, and funding will determine which technique to use.
\end{abstract}

Keywords: Pollen analyses, scanning electron microscopy, light microscopy, soil analysis

Palynologists rely on light microscopy (LM) to identify and interpret the pollen spectrum of a particular sample. Scanning electron microscopy (SEM) is not normally used for counting and identifying pollen grains. Instead, SEM is mainly used for morphological comparisons and taxonomy where the increased resolution of SEM makes differentiation of pollen grains and taxa more obvious (for example The Northwest European Pollen Flora I-VIII (Punt, 1976; Punt \& Clarke, 1980, 1981, 1984, 1988; Punt \& Blackmore, 1991; Punt et al., 1995; Blackmore et al., 2003), Pollen et spores d'Europe et d'Afrique du Nord Series (Reille, 1992, 1995, 1998, 1999), and in Grayum's contribution, 1992) and as an aid in taxonomy (Skvarla
\& Larson, 1965; Ridgeway \& Skvarla, 1969). Scanning electron microscopy of pollen is also used to create new terminology for describing pollen ornamentation (Rowley et al., 1988; Vezey \& Skvarla, 1990; Vezey et al., 1991), developing a numerical approach to pollen sculpturing (Vezey et al., 1991), and even computer analysis of the exine (Vezey \& Skvarla, 1990).

Some modern palynological textbooks include SEM micrographs of pollen (Ogden et al., 1974; Moore et al., 1991); however, the majority focuses only on LM (Herrera \& Urrego, 1996; Beug, 2004). Likewise, some atlases include SEM micrographs (Nilsson et al., 1977; Bassett et al., 1978; Moar, 1993; Qiao, 2005) and only a few solely use SEM

Correspondence: Gretchen D. Jones, Areawide Pest Management Research Unit (APMRU), ARS United States of Agriculture, 2771 F\&B Road, College Station, TX 77845, U.S.A. E-mail: g-jones@tamu.edu 
micrographs for the pollen presentation (Adams \& Morton, 1972, 1974, 1976, 1979; Bambara \& Leidy, 1991; Jones et al,. 1995; Wei et al., 2003).

Most entomopalynological (study of pollen on/in insects) studies use LM for pollen analyses (Jones \& Coppedge, 1998). However, SEM is better for examining the pollen that adheres to insects, such as moths and butterflies (Lepidoptera). Since much of that pollen is on the proboscis, legs, thorax and head (Bryant et al., 1991), the samples can be mounted on SEM stubs and examined without processing. In these types of SEM studies, pollen identification is used to determine migration and dispersal routes, insect source zones and examine feeding resources (Hendrix et al., 1987; Benedict et al., 1991; Hendrix \& Showers, 1992; Gregg, 1993; Lingren et al., 1993, 1994; Del Socorro \& Gregg, 2001; Gregg et al., 2001).

Van Laere et al. (1969) saw the promise of SEM in such studies and even suggested that SEM might be an important technique for analyzing honey. Chen and Shen (1990) used SEM to examine the pollen of Formosan honey. However, they did not use SEM to make counts and pollen identifications.

Blackburn and Ford (1993) used SEM micrographs of filtered honey to determine the abundance of each pollen type in the honey. The abundance was calculated by placing a $1 \mathrm{~cm}^{2}$ acetate grid over each micrograph. Unfortunately, there is no information about the actual pollen counts or pollen diversity.

Regardless, SEM is not routinely used in palynology and is seldom used to make pollen counts or pollen identification. In some situations the lack of availability and/or lack of funding may prevent the use of SEM. Nevertheless, if both LM and SEM were available, which should be chosen to conduct a pollen analysis of a single sample? We could not find any published comparisons between LM and SEM pollen counts and pollen identifications of the same sample, or any information about using SEM for sediment samples. The purpose of this research was to test and determine the advantages and disadvantages of each technique (LM and SEM), and to compare the pollen counts and pollen identifications from the same sample.

\section{Material and methods}

A surface sample $(3.0 \mathrm{~g})$ was collected following Adam and Mehringer (1975) in Tirana, Albania by mixing 30 individual "pinches" from the uppermost layer of soil at different locations within a $10 \mathrm{~km}^{2}$ area. Unless otherwise stated, the sample was always centrifuged for $3 \mathrm{~min}$ at $1060 \times \mathrm{g}$., the supernatant decanted, and resulting residue mixed (vortexed) on a vortex stirrer for $30 \mathrm{~s}$ after each step.

\section{Pollen extraction}

One-half of the soil sample (1.5 g) was examined for pollen. One tablet of Lycopodium clavatum L. spores (Figure 1A) was dissolved in 5 drops of concentrated hydrochloric acid $(\mathrm{HCl})$ for 5 min then added to the sample. The beaker containing the spores was rinsed twice with $95 \%$ ethyl alcohol $(\mathrm{ETOH})$, and the rinse added to the sample.

The sample was then rinsed with glacial acetic acid.

Five $\mathrm{ml}$ of an acetolysis mixture (Erdtman, 1960) was added to the subsample. The subsample was heated for $6 \mathrm{~min}$ at $80^{\circ} \mathrm{C}$ in a pre-heated hot block. After which $5 \mathrm{ml}$ of glacial acetic acid were added.

The subsample was rinsed with glacial acetic acid followed by two distilled water rinses. After each rinse the sample was centrifuged, decanted, and vortexed.

Four $\mathrm{ml}$ of zinc bromide $\left(\mathrm{ZnBr}_{2}\right)$ (specific gravity of 1.9) was added, and then thoroughly mixed into the subsample for one min. Afterwards, an additional $5 \mathrm{ml}$ of $\mathrm{ZnBr}_{2}$ was mixed into the subsample. The subsample was centrifuged for $5 \mathrm{~min}$ at $212 \times \mathrm{g}$, and then for $5 \mathrm{~min}$ at $1060 \times \mathrm{g}$. The dark band of material (pollen residue) that formed on the surface after centrifugation was removed. It consisted of about $2 \mathrm{ml}$ of fluid.

To reduce the specific gravity of the removed pollen residue, $40 \mathrm{ml}$ of $95 \%$ ETOH (specific gravity of 0.79 ) were added to the pollen residue. The pollen residue was concentrated using centrifugation.

The sample was rinsed twice with $95 \% \mathrm{ETOH}$.

One drop of the pollen reside was pipetted onto a SEM stub that was previously coated with TEMPFIX ${ }^{\circledR}$ adhesive. Three stubs were made, each with a single drop of the pollen residue.

Several drops of safranin-O stain and $8 \mathrm{ml}$ of $95 \%$ ETOH were added to the remaining pollen residue. After centrifuging, decanting, and vortexing, the residue was transferred to a one-dram, glass vial. Five drops of glycerin were stirred into the vial and the vial was placed on a warm hot plate at $27^{\circ} \mathrm{C}$ overnight.

\section{LM preparation}

Before making each slide, the pollen residue was vortexed for 30 s (Jones \& Bryant, 1998). One drop of residue was placed on a glass slide, allowed to spread, then covered with a cover slip, and the slide sealed.

\section{SEM preparation}

Stubs were coated with $400 \AA$ of gold palladium in a Hummer II sputter coater. Marks for repositioning 

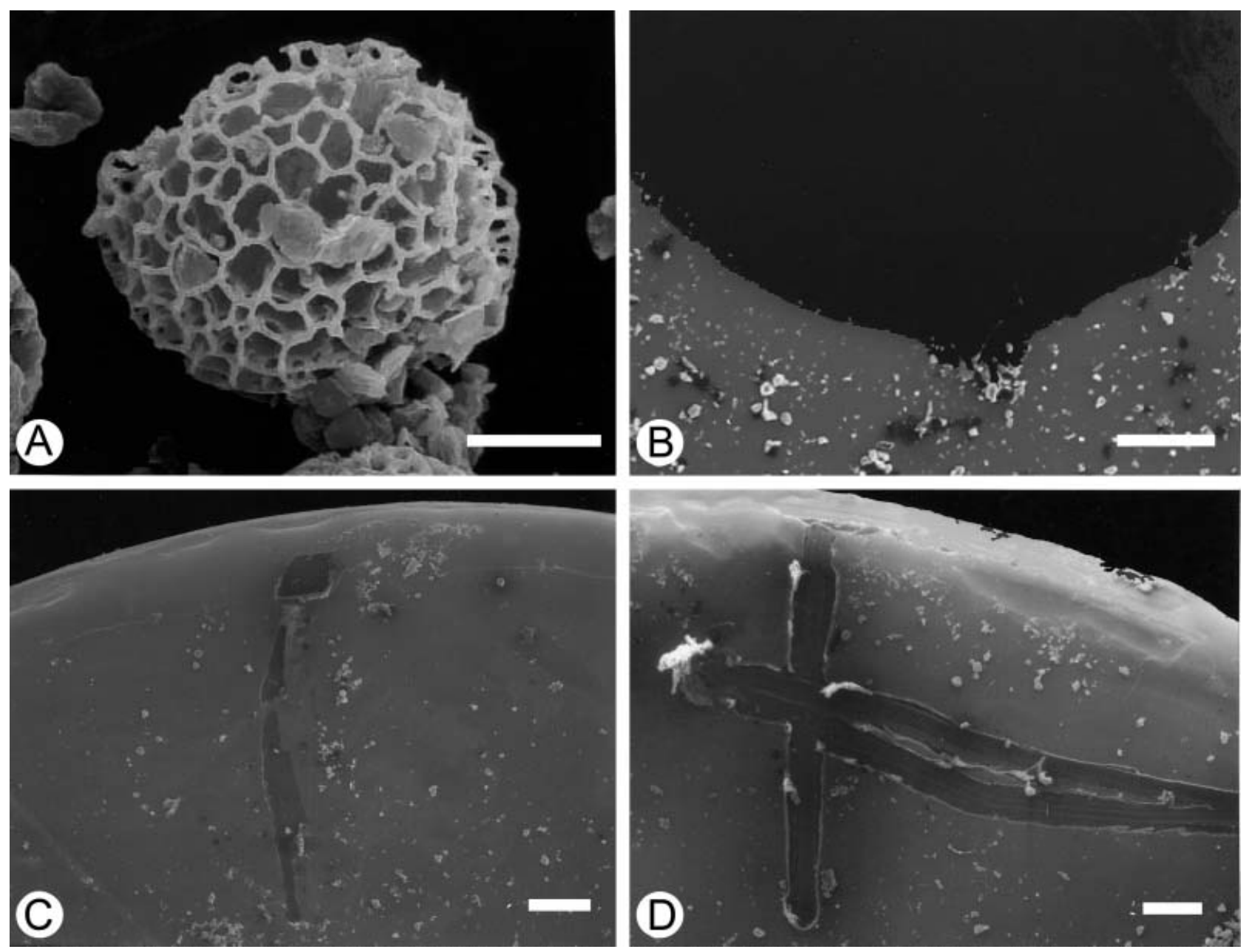

Figure 1. (A) Lycopodium clavatum L. spore that was added as a tracer; (B) SEM after-coating mark made with nail polish; (C) SEM aftercoating mark made with a pair for forceps; (D) SEM after-coating mark made with a diamond probe. Scale bars - $20 \mu \mathrm{m}$ (A); $200 \mu \mathrm{m}$ (B, D); $100 \mu \mathrm{m}(\mathrm{C})$.

of the stub were added before and after coating. Marks made prior to coating included numbers or letters added to the sides, top, and bottom of the stub with a permanent marker. Marks made after coating included a drop of glitter nail polish (Figure 1B), an "i" made with a pair of forceps (Figure 1C), or a "+" made with a diamond scribe (Figure 1D). Stubs were examined in a JEOL JSM-6400 scanning electron microscope using an operating voltage of $15 \mathrm{kV}$ and a working distance of $15 \mathrm{~mm}$.

\section{LM and SEM analyses}

Four 300-grain pollen counts were made. One count was made from each of the two prepared glass slides, and one from each of two of the three prepared SEM stubs.

Pollen grains viewed with SEM were put into three categories. Grains where most of the diagnostic features could be seen were placed into Category 1 "identifiable" (Figure 1A). Grains in Category 2 were labeled "obscured". Pollen in this category included grains that were sufficiently covered by debris so that many key ornamentation and/or aperturation details were partially obscured or were in a poor orientation (Figure 2A).

Category 3 grains were considered "virtually impossible to identify". This category included grains that were badly degraded, severely broken, crumpled, badly folded, or so obscured by debris that sufficient morphological details were not visible (Figure 2B).

\section{Pollen identification}

Pollen identifications were made utilizing the USDA Areawide Pest Management Research Unit (APMRU) Modern Pollen Reference Collections, the Texas A \& M University Palynology Laboratory Modern Pollen Reference Collection (TAMU), and comparisons with images in a number of published pollen atlases. 


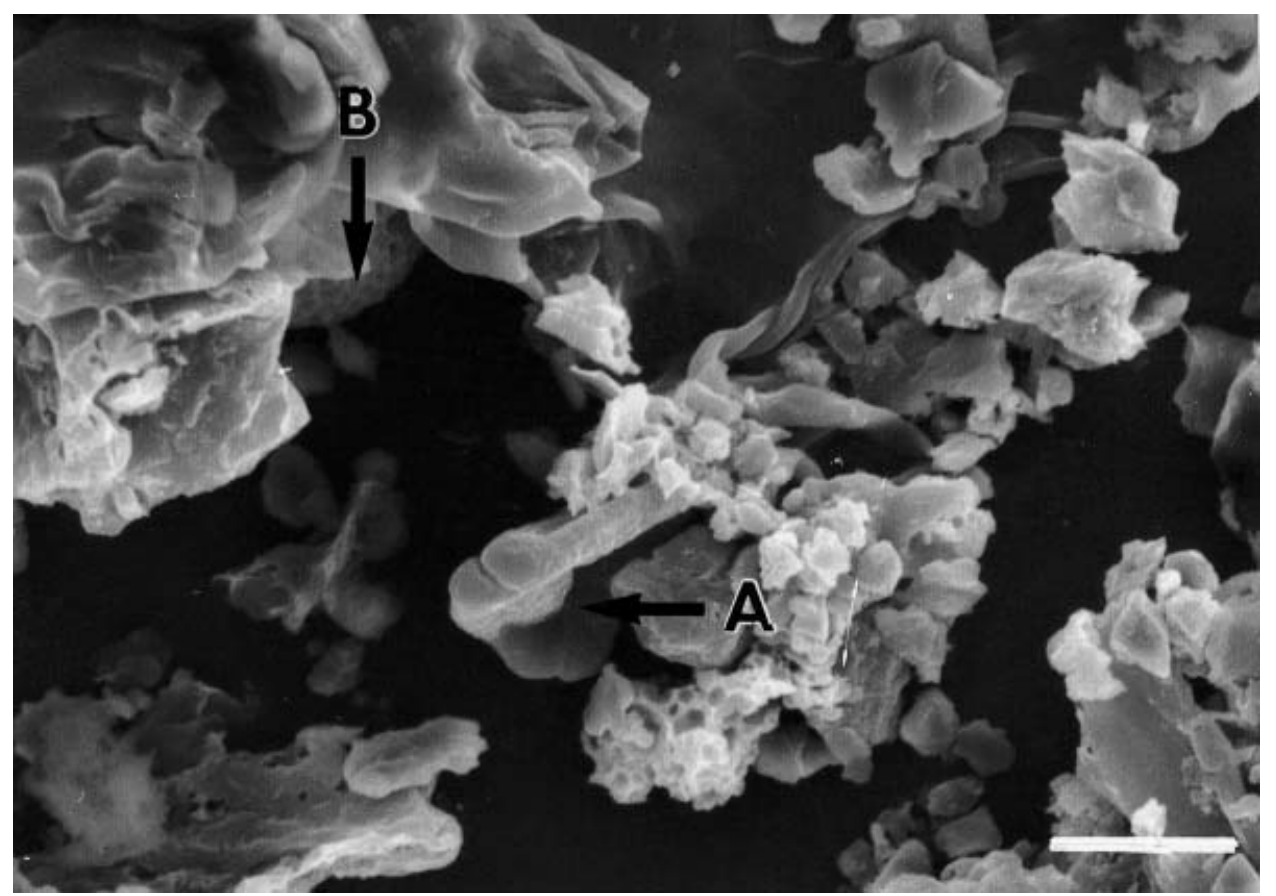

Figure 2. Two pollen grains from the SEM studies. (A) A Category 2 pollen grain "obscured" by a poor orientation for identification; (B) A Category 3 pollen grain "virtually impossible to identify" is so obscured by debris that identification is extremely difficult. Scale bar - $10 \mu \mathrm{m}$.

For SEM analyses, when a pollen grain's ornamentation looked different from other grains in the same family or genus, it was considered to represent a different taxon. Several different pollen types in the genera Ligustrum, Tilia, and Plantago were distinguishable during SEM analyses but were not initially apparent during LM analyses. During the SEM analyses, the pollen in each genus was separated into species or groups called "types." To make the counts comparable, the number of pollen grains for the different types of Ligustrum, Tilia, and Plantago are lumped together in a genus ranking. For example, three different types of Tilia pollen were apparent during the SEM analyses but not during the LM. Therefore, there is a Tilia SEM total that is a summation of the number of pollen grains from each of the three Tilia types.

Asteraceae. The sunflower plant family is the largest vascular plant family with over 1,525 genera and over 22,750 species (Mabberley, 1997). Assigning specific genera to the pollen in this vast group is difficult even though each species has its own unique morphology. Nevertheless, some broad pollen groups were used. These groups included Artemisia, and Cichorioideae, both of which are distinguishable.

Martin (1963) split the pollen of the subfamily Asteroideae into two major groups based on the length of the surface "spines." Asteroideae pollen with surface "spines" longer than 2.5 um were categorized as a high "spine" (HS) group, and those with shorter "spines" were put into a low "spine" (LS) group.

Myrtaceae. This large family of tropical and subtropical plants contains over 130 genera and more than 4,600 species (Mabberley, 1997). Since the $1800 \mathrm{~s}$, members of this family have been exported as ornamental or timber trees to tropical and subtropical regions of the world. Most of the pollen types in the Myrtaceae share similar morphological characteristics. However, with SEM, different Myrtaceae pollen grains were initially separated into distinctive types. Similar to Ligustrum, Tilia, and Plantago for comparison between LM and SEM counts, there is a Myrtaceae SEM total that is a summation of the number of pollen grains from each Myrtaceae type.

\section{Pollen statistics}

The number of taxa was totalled for each technique (LM and SEM), a grand total was summed, and pollen concentration values were calculated using the following formula:

(number pollen grains counted $) \times($ number of tracer spores added $)$ $\overline{(\text { number of grams of sample processed }) \times(\text { number tracer spores counted })}$

ANOVA and t-tests were used to compare the 
number of taxa among the counts and between the two techniques (Jones \& Bryant, 2001, 2004).

\section{Results and discussion}

\section{SEM analysis}

Prior to examining the first stub, a palynologist using SEM for pollen analyses must decide two main things. First, the palynologist must decide which type of photomicroscopy medium to use. Secondly, the palynologist must determine how to reposition a stub if the count is interrupted and the stub must be removed and replaced at a later time.

Micrographs can be made with film and/or digitally. Two types of film are used for SEM: negative and positive. The advantage of using negative film is the cost, generally about $\$ 0.50$ to 0.70 (U.S.A) per sheet (Table I). The resolution is much better than positive film. It is also easier to make enlargements and multiple copies from negative film than from positive film. The disadvantages of negative film include the developing time and uncertainty of the quality of the image at the time the micrograph is taken (Table I).

The main advantage of positive film is time (about $45 \mathrm{~s}$ ) and the "instant" micrograph that is generated (Table I). However, positive film is expensive costing about $\$ 2.00$ to 3.00 (U.S.A.) per micrograph. In addition, numerous copies and/or enlargements are difficult to make because there is no negative.

Newer SEM models can use digital imagery for generating micrographs. One advantage of digital imagery is that the image is already digitized so that image manipulation (i.e., removal of debris) and enhancement (i.e., color, contrast, and brightness) are easy (Table I). Some computer software programs even allow the viewing of numerous micrographs at one time making the comparison of two or more pollen grains easy.

Table I. Advantages and disadvantages of negative and positive film and digital imagery for pollen microscopy.

\section{NEGATIVE FILM}

\section{Advantages}

1. Good resolution and clear micrographs

2. Can correct contrast/brightness when printing

3. Can remove some debris from micrograph when printing

4. Can make as many prints as desired

5. Can enlarge the negative or small areas to whatever size needed without false magnification

6. Have multiple copies (negative and print) so if one gets lost, the data are not

7. Will last for 50-100 years or longer
Disadvantages

Do not get an instant micrograph for comparisons

More time consuming, (i.e. development of film, prints).

Can be sensitive to light, fungi, etc

Problems when developing can cost time and money

Not sure what the negative will look like until it is developed

If the negative isn't usable, it is difficult to find the exact pollen grain again

\section{POSITIVE FILM}

\section{Advantages}

1. Instant micrograph

2. Can quickly be used for pollen comparisons, counts, etc.

3. Faster than negative film for obtaining prints

4. Good to show clients

5. Chemical exposure is much less

6. Do not have to stand in a darkroom for long periods of time to develop negatives and prints

7. Once digitized can remove debris, enhance contrast, etc.

\author{
Expensive \\ Micrograph must be digitized to make multiple copies \\ Resolution is not as good as negative film \\ It is the only copy so if lost so are the data \\ If past expiration date, may not produce a good micrograph \\ Brightness/contrast levels may be incorrect so may need to take multiple \\ micrographs
}

\section{DIGITAL IMAGERY}

\section{Advantages}

1. Micrograph is already digitized

2. Easy to email, add to manuscripts, etc.

3. Various software can be used to remove debris, adjust contrast/brightness, etc.

4. Can put multiple micrographs on a screen for comparison

5. No exposure to chemicals for making micrographs

6. Do not have to stand in a darkroom for long periods of time to develop negatives and prints

\section{Disadvantages}

Amount of storage need for each high quality micrograph

Cost of computer hardware, storage devices, software, etc.

Technology advances may reduce the life of storage devices (CD, DVD, etc.)

Resolution is not as good as negative film

It is the only copy so if lost so are the data

Time needed to learn image analysis software packages 
Some disadvantages of digital imagery include the large amount of memory needed for each micrograph, disk storage space needed (hard disk, CDs or DVDs), and the initial cost for computer, software, etc. Obtaining a high quality resolution micrograph took about $4 \mathrm{~min}$. The resolution of the printed digital image was not a good as the same images taken with either negative or positive film. The JEOL SEM used for this manuscript is over 15 year old. No doubt there have been many improvements in the digital imagery system of newer SEM scopes.

Printing compound photographic plates from digital images was difficult. Trying to match the contrast and brightness for each print was time consuming and used a lot of photographic printer paper and ink. Putting four micrographs together to be printed on one photographic sheet was not an option in the software used to generate micrographs for this manuscript. Therefore no matter how large or small the final micrograph, a whole sheet of paper had to be used. Finally, the heat press used to attach a print and adhesive to a mounting board scratched, melted, and scarred the micrograph made from the computer regardless of how low the temperature was. This is most likely due to the heat sensitivity of the ink used for most computer printers. There are other types of techniques such as spray adhesives that can be used to put micrographs made from computer printers onto plates for publication and exhibition.

Because the objective of this study was to compare LM and SEM pollen counts and identifications, it was important to have instant access to the different pollen types. Therefore, positive film was used for the SEM analyses. The positive micrographs were put into plastic photo holders, placed into a 3-ring binder, and arranged by ornamentation then aperaturation. This binder was kept next to the SEM so that new grains could be compared to previously photographed ones. Over $200 \mathrm{LM}$ and over 150 SEM pollen micrographs were taken during the counts.

Pollen counting. Re-positioning the SEM stub in the exact location to continue a count is next to impossible. To allow exact repositioning, marks were made prior and after coating the stub. Marking prior to coating did not work because the coating covered the marks that were made on the top and sides of the stub. Marks on the bottom of the stub were not covered by the coating but were hidden when the stub was put in the specimen holder making re-positioning impossible.

The after-coating mark made with the nail polish (Fig. $1 \mathrm{~B}$ ) was the easiest to apply because a drop of nail polish could be added without picking up and holding the stub. Once applied, the nail polish had to dry for several days before the stub could be examined. Unfortunately, the nail polish mark was the most difficult mark to use to consistently reposition the stub in the same location. In addition, there was concern that the drop may obscure important pollen types.

Marking with the forceps worked well (Figure 1C). However, several forceps were bent during the marking process. If forceps are used, they should be a coarse type that does not easily bend. The " $i$ " made with the forceps was easily seen but could be mistaken as an accidental scratch on the stub by an inexperienced technician.

Marking with a diamond scribe worked best (Figure 1D). Diamond scribes are common in palynological laboratories and are used for marking numbers or codes on vials and glassware. Virtually any type of mark can be made with a diamond scribe. The " $t$ " made with the diamond probe was more obvious when examining the stub (Figure 1D) than the "i" (Figure 1C) made with the forceps. Also, the cross bars of the " $t$ " helped in repositioning the stub correctly each time.

Pollen data interpretation and LM/SEM comparison. Debris in a pollen sample is common and something palynologists work around. When using glycerine and LM, a pollen grain usually can be separated from the debris by gently rolling it around. Debris on the stub can partially or entirely cover a pollen grain. When the diagnostic features are hidden, identification of the pollen grain can be impossible. To calculate the difficulty in pollen identification during SEM analyses, pollen grains seen with the SEM were put into three categories: Category 1 "identifiable" (Figure 1A), Category 2 "obscured" (Figure 2A) and Category 3, "virtually impossible to identify" (Figure 2B).

Overall, the majority of the pollen grains counted with the SEM (86\%) were classified as either Category 1 or 2 (calculated from Table II). Only $14 \%$ of the grains were considered to be in Category 3.

In the SEM Pollen Counts \#1 and \#2, over $50 \%$ of the grains were classified as Category 1 (54 and $70 \%$ respectfully, Table II). Category 3 contained the fewest number of pollen grains in both SEM counts (16 and 12\%, respectfully, Table II).

All of the pollen in Category 1 was identified or in a few cases some were listed as unknown types. The unknown category was used for pollen grains that were identifiable provided there were sufficient SEM images to match the unknown type. 
Table II. Comparison of the identification quality of pollen grains when using SEM.

\begin{tabular}{lcccccc}
\hline Categories & $\begin{array}{c}\text { Count } 1 \\
\text { Actual \# }\end{array}$ & $\begin{array}{c}\text { Percent } \\
\text { of count }\end{array}$ & $\begin{array}{c}\text { Count } 2 \\
\text { Actual \# }\end{array}$ & $\begin{array}{c}\text { Percent } \\
\text { of count }\end{array}$ & $\begin{array}{c}\text { Overall total } \\
\text { Percent of } \\
\text { overall total }\end{array}$ \\
\hline Category 1 & 162 & 54.0 & 211 & 70.3 & 373 & 62.2 \\
Category 2 & 91 & 30.3 & 54 & 18.0 & 142 & 23.7 \\
Category 3 & 47 & 15.6 & 35 & 11.7 & 82 & 13.7 \\
\hline Total & 300 & 100.0 & 300 & 600 & 100 \\
\hline
\end{tabular}

Pollen grains in Category 2 were not easy to identify. In most cases, only an expert familiar with the pollen taxa in the sample and with what pollen grains look like with SEM could identify these grains with certainty. Eventually, all but a very few of the Category 2 pollen grains were identified and assigned to a specific taxon.

Category 3 pollen were grains that were degraded, severely broken, crumpled, badly folded, or so obscured by debris that insufficient morphological detail was visible. Nevertheless, many Category 3 grains were identified. However, it took days and sometimes weeks of examining the micrographs, many at high magnification, and comparing them with hundreds of other micrographs. The main factors that influence identification of Category 3 pollen are time, funding, and the condition of the pollen grain (how many of the diagnostic feature are hidden).

Since Category 3 grains made up only $16 \%$ and $12 \%$ of the total, they normally will not affect the final pollen interpretation. In cases involving forensics, the time and money involved may be worth the effort to identify Category 3 pollen grains.

Tracer spores and pollen concentration values. A comparison of the LM and SEM pollen counts and identifications would not be complete without comparing concentration values. We selected Lycopodium clavatum spores because there was no record of this plant growing in or near the sampled area.

Maher (1981) indicated that the ratio of pollen grains in a sample should not exceed twice the number of tracer spores added before processing. The most efficient pollen/marker ratio that gives the greatest precision for the least amount of counting is when the ratio of pollen to tracer spores is at or close to $2: 1$. Furthermore, the greater the ratio of pollen to tracer spores beyond 2:1, the larger number of pollen and tracer spores must be counted to obtain the same level of accuracy provided by smaller counts with ratios of $2: 1$ or less. When a sample is pollen rich and only a minimal number of tracer spores are added, encountering even one additional tracer spore during a count drastically changed the pollen concentration value (Maher, 1981).
Previous studies of surface samples (Bryant et al., 1994; Mack \& Bryant, 1974) contained no more than $20,000-25,000$ pollen grains per gram. We did not want to "overwhelm" the potential pollen in the soil sample with too many tracer spores; therefore, one tablet containing $13,500 \pm 500$ tracer spores was added.

Pollen concentration values ranged from a low of 385,714 (LM Count \#2) to a high of 900000 (SEM Count \#1) per gram of soil (Table III). Because this sample contained such a prolific amount of pollen and the number of tracer spores added was underestimated, the pollen concentration values varied greatly among the four counts (Table III).

The abundance of pollen in this soil sample was a surprise and represents the highest pollen concentration value either of us has found in similar surface samples. This high pollen concentration value is expected in samples collected from sediments where preservation conditions are ideal, such as acidic peat bogs or samples collected in the middle of a pine forest shortly after the pines shed their pollen.

Taxa diversity. Regardless which microscope was used or which count examined, the same three taxa (Ligustrum spp., Myrtaceae-type, and Tilia spp.) had the greatest number of pollen grains. The top three taxa in the LM analyses were Tilia spp. (28 and 23\%), Ligustrum spp. (27 and 32\%), and Myrtaceaetype (20 and $17 \%$ ) (Table III), while the top three found in the SEM analyses were Myrtaceae-type (27 and $13 \%$ ), Tilia spp. (18 and 22\%), and Ligustrum spp. (15 and 36\%) (Table III).

The variations in the pollen grain numbers among the counts may have resulted from the size of Myrtaceae pollen grains. Myrtaceae-type pollen is small and may not have been drawn up very far into the pipette when preparing the SEM stub. Thus, those grains would have been expelled first when the stub was made. This would also affect the LM counts because the slides were made from the remaining residue after the SEM stubs were prepared. Removal of the smaller Myrtaceae grains during the stub preparation would lessen their numbers in the remaining sample for the LM analyses.

The number of taxa found in each count ranged from 22 (LM Count \#1) to 52 in (SEM count \#2, 
Table III. Family, taxon, actual grain counts (NOG), and the percentage of each taxon in the count (POG) made with light (LM) and scanning electron (SEM) microscopy. LM/SEM total represents the actual pollen count from LM and the summed total for all the types in that category made from SEM.

\begin{tabular}{|c|c|c|c|c|c|c|c|c|c|}
\hline \multirow[b]{3}{*}{ Family } & \multirow[b]{3}{*}{ Taxon or type } & \multicolumn{4}{|c|}{$\mathrm{LM}$} & \multicolumn{4}{|c|}{ SEM } \\
\hline & & \multicolumn{2}{|c|}{ Count 1} & \multicolumn{2}{|c|}{ Count 2} & \multicolumn{2}{|c|}{ Count 1} & \multicolumn{2}{|c|}{ Count 2} \\
\hline & & NOG & POG & NOG & POG & NOG & POG & NOG & POG \\
\hline Aceraceae & Acer & & & & & & & 1 & 0.3 \\
\hline Arecaceae & & & & & & 1 & 0.3 & & \\
\hline Asteraceae & Cichorioideae type & & & & & 2 & 0.7 & & \\
\hline Asteraceae & Asteroideae LS type & 2 & 0.7 & 3 & 1.0 & & & & \\
\hline Asteraceae & Asteroideae HS type & 1 & 0.3 & 1 & 0.3 & & & & \\
\hline Berberidaceae & & & & & & & & 1 & 0.3 \\
\hline Betulaceae & Carpinus & 5 & 1.7 & 3 & 1.0 & 5 & 1.7 & 3 & 1.0 \\
\hline Betulaceae & Alnus & 1 & 0.3 & 1 & 0.3 & 2 & 0.7 & 3 & 1.0 \\
\hline Betulaceae & Betula & & & & & 3 & 1.0 & 2 & 0.8 \\
\hline Brassicaceae & & & & 1 & 0.3 & 1 & 0.3 & 1 & 0.3 \\
\hline Caprifoliaceae & Lonicera & & & 2 & 0.7 & & & & \\
\hline Caryophyllaceae & & & & & & 1 & 0.3 & & \\
\hline Chenopod./Amar. & Cheno-Ams & & & 3 & 1.0 & 3 & 1.0 & 2 & 0.6 \\
\hline Cupressaceae & & 2 & 0.7 & 2 & 0.7 & 11 & 3.7 & 4 & 1.4 \\
\hline Cupressaceae & Funiperus & & & & & & & 1 & 0.3 \\
\hline Ericaceae & & 1 & 0.3 & 1 & 0.3 & & & & \\
\hline Ericaceae & SEM type 1 & & & & & & & 1 & 0.3 \\
\hline Ericaceae & SEM type 2 & & & & & & & 1 & 0.3 \\
\hline Fabaceae & Acacia & 1 & 0.3 & & & & & 1 & 0.3 \\
\hline Fabaceae & Melilotus & & & 1 & 0.3 & 1 & 0.3 & 1 & 0.3 \\
\hline Fabaceae & SEM type 2 & & & & & 1 & 0.3 & 1 & 0.3 \\
\hline Fagaceae & Castanea & 5 & 1.7 & 3 & 1.0 & 4 & 1.3 & 2 & 0.6 \\
\hline Fagaceae & Fagus & & & & & 1 & 0.3 & 3 & 1.0 \\
\hline Fagaceae & Quercus & 1 & 0.3 & 1 & 0.3 & 5 & 1.7 & 4 & 1.4 \\
\hline Juglandaceae & Fuglans & & & 1 & 0.3 & & & & \\
\hline Liliaceae & Erythronium & & & & & 1 & 0.3 & & \\
\hline Liliaceae & & & & & & & & 1 & 0.3 \\
\hline Malvaceae & & 1 & 0.3 & & & & & & \\
\hline Myrtaceae & LM/SEM total & 60 & 20.1 & 50 & 16.7 & 82 & 27.3 & 40 & 13.3 \\
\hline Myrtaceae & SEM type 2 & & & & & 52 & 17.3 & 33 & 11.0 \\
\hline Myrtaceae & SEM type 3 & & & & & 24 & 8.0 & 6 & 1.9 \\
\hline Myrtaceae & SEM type 1 & & & & & 3 & 1.0 & 1 & 0.3 \\
\hline Myrtaceae & SEM type 4 & & & & & 1 & 0.3 & & \\
\hline Myrtaceae & SEM type 5 & & & & & 2 & 0.7 & & \\
\hline Oleaceae & $\begin{array}{l}\text { Ligustrum LM/ } \\
\text { SEM total }\end{array}$ & 80 & 26.8 & 96 & 32.0 & 46 & 15.3 & 108 & 36.0 \\
\hline Oleaceae & $\begin{array}{l}\text { Ligustrum SEM type } \\
1\end{array}$ & & & & & 10 & 3.3 & 5 & 1.7 \\
\hline Oleaceae & $\begin{array}{l}\text { Ligustrum SEM type } \\
2\end{array}$ & & & & & 31 & 10.3 & 97 & 32.3 \\
\hline Oleaceae & $\begin{array}{l}\text { Ligustrum SEM type } \\
3\end{array}$ & & & & & 5 & 1.7 & 6 & 2.0 \\
\hline Oleaceae & Olea & 12 & 4.0 & 20 & 6.7 & 20 & 6.7 & 19 & 6.4 \\
\hline Oleaceae & Syringa vulgaris & & & & & 3 & 1.0 & 6 & 2.0 \\
\hline Pinaceae & $\begin{array}{l}\text { Pinus - Diploxylon } \\
\text { type }\end{array}$ & 1 & 0.3 & 1 & 0.3 & & & & \\
\hline Pinaceae & $\begin{array}{l}\text { Pinus - Haploxylon } \\
\text { type }\end{array}$ & 1 & 0.3 & 1 & 0.3 & & & & \\
\hline Pinaceae & Undetermined type & 19 & 6.4 & 14 & 4.7 & 14 & 4.7 & 11 & 3.6 \\
\hline Plantaginaceae & $\begin{array}{l}\text { Plantago LM/SEM } \\
\text { total }\end{array}$ & 1 & 0.3 & 1 & 0.3 & 12 & 4.0 & 7 & 2.5 \\
\hline Plantaginaceae & Plantago SEM type 1 & & & & & 2 & 0.7 & & \\
\hline Plantaginaceae & Plantago SEM type 2 & & & & & 10 & 3.3 & 5 & 1.7 \\
\hline Plantaginaceae & Plantago SEM type 3 & & & & & & & 2 & 0.8 \\
\hline Poaceae & & 13 & 4.4 & 12 & 4.0 & 19 & 6.3 & & \\
\hline Poaceae & Zea & & & & & 1 & 0.3 & & \\
\hline Polygonaceae & Rumex & & & & & 2 & 0.7 & & \\
\hline Ranunculaceae & Caltha palustris & & & & & 1 & 0.3 & 2 & 0.6 \\
\hline
\end{tabular}


Table III. Continued

\begin{tabular}{|c|c|c|c|c|c|c|c|c|c|}
\hline \multirow[b]{3}{*}{ Family } & \multirow[b]{3}{*}{ Taxon or type } & \multicolumn{4}{|c|}{$\mathrm{LM}$} & \multicolumn{4}{|c|}{ SEM } \\
\hline & & \multicolumn{2}{|c|}{ Count 1} & \multicolumn{2}{|c|}{ Count 2} & \multicolumn{2}{|c|}{ Count 1} & \multicolumn{2}{|c|}{ Count 2} \\
\hline & & NOG & POG & NOG & POG & NOG & POG & NOG & POG \\
\hline Ranunculaceae & & & & 1 & 0.3 & 1 & 0.3 & & \\
\hline Rhamnaceae & & & & & & & & 2 & 0.6 \\
\hline Rutaceae & Citrus & & & 1 & 0.3 & & & & \\
\hline Salicaceae & Populus & & & 1 & 0.3 & & & & \\
\hline Saxifragaceae & Saxifraga & & & 1 & 0.3 & & & & \\
\hline Sparganiaceae & Sparganium & & & & & & & 1 & 0.3 \\
\hline Tiliaceae & Tilia LM/SEM total & 83 & 27.9 & 70 & 23.3 & 52 & 17.7 & 67 & 22.3 \\
\hline Tiliaceae & Tilia SEM type 1 & & & & & 32 & 10.7 & 40 & 13.3 \\
\hline Tiliaceae & Tilia SEM type 2 & & & & & 4 & 1.3 & 4 & 1.4 \\
\hline Tiliaceae & Tilia SEM type 3 & & & & & 16 & 5.3 & 23 & 7.7 \\
\hline Ulmaceae & Ulmus & & & 2 & 0.7 & & & & \\
\hline Vitaceae & Parthenocissus & & & & & 1 & 0.3 & 1 & 0.3 \\
\hline Vitaceae & Vitis & & & 1 & 0.3 & & & & \\
\hline SEM Unknown 1 & & & & & & 1 & 0.3 & & \\
\hline SEM Unknown 2 & & & & & & & & 3 & 1.0 \\
\hline SEM Unknown 3 & & & & & & 1 & 0.3 & & \\
\hline SEM Unknown 4 & & & & & & 1 & 0.3 & & \\
\hline SEM Unknown 5 & & & & & & 1 & 0.3 & & \\
\hline LM Unknown A & & 3 & 1.0 & & & & & & \\
\hline LM Unknown B & & & & 2 & 0.7 & & & & \\
\hline LM Unknown C & & 3 & 1.0 & & & & & & \\
\hline $\begin{array}{r}\text { Degraded (ID } \\
\text { impossible) }\end{array}$ & & 2 & 0.7 & 3 & 1.0 & & & & \\
\hline Lycopodium spores & & 3 & & 7 & & 3 & & 5 & \\
\hline Total number of taxa & & 22 & & 30 & & 41 & & 52 & \\
\hline Total number of grains & & 298 & & 300 & & 300 & & 300 & \\
\hline $\begin{array}{l}\text { Pollen concentration } \\
\text { values }\end{array}$ & & 894,000 & & 385,714 & & 900,000 & & 540,000 & \\
\hline
\end{tabular}

SEM taxa separated) (Table III). Some taxa were found only in the SEM analyses and other only in the LM analyses (Table III).

Likewise, when all taxa from both counts for each technique (LM vs. SEM) are examined, more taxa were found in the SEM counts (52) than in the LM counts (33) (Table III). This is primarily due to the increased resolution of the SEM, which enabled similar looking taxa to be separated.

A total of 73 pollen taxa were found in the four counts (Table IV). Nine taxa were found in all the LM and SEM counts (Table IV). These included not only the three most dominant types: Tilia, Ligustrum, and Myrtaceae-type, but also minor types such as: Carpinus, Alnus, Olea, Castanea, Pinus, Plantago, and pollen in the Cupressaceae. Some taxa such as fuglans sp. were found only in the LM counts, and others, such as Fabaceae SEM type 2, were only found in the SEM counts. Seventeen taxa (17) were found in only the LM analyses while 28 taxa were found only in the SEM analyses (Table IV).

After the end of the SEM counts, the unexamined portion of both stubs (approximately $1 / 2$ of the surface) and the unexamined third stub were scanned for new taxa. Twenty (20) new taxa were found that were not previously encountered during the SEM counting process (Table V) bringing the grand total of taxa to 93 . Some of these taxa were airborne types such as Typha angustifolia L. and Platanus sp., while others were entomophilous types such as Trifolium sp. and Aesculus sp.

Of the 93 total taxa, $22 \%$ were not encountered in the 1,198 pollen grains counted (calculated from Tables III and V). Light microscopy accounted for $56 \%$ of the total number of taxa, while SEM accounted for $79 \%$. Undoubtedly, the additional 20 taxa missed during one of the four counts represent minor pollen taxa in the soil sample. Nevertheless, some of those minor pollen taxa might be critical data in identifying minor vegetation components, in identifying a unique, geographical location; or being an important factor in forensic investigations.

It is not surprising that SEM accounted for more taxa, nor that some of the pollen taxa appeared only in the LM counts while other taxa appeared only in the SEM counts. Finding pollen in any mixed surface soil, fossil sediments, or honey sample is essentially a "hit or miss" attempt. After processing a sample for analysis, and then preparing a slide or SEM stub for counting, the 
Table IV. The total number of pollen grains (NOG) and percentage (POG) of grains per taxon for the LM and SEM counts and an over all total number of each taxon pollen grains and its percentage. LM totals do not include degraded grains.

\begin{tabular}{|c|c|c|c|c|c|c|c|}
\hline \multirow[b]{2}{*}{ Family } & \multirow[b]{2}{*}{ Taxon or type } & \multicolumn{2}{|c|}{ LM Totals } & \multicolumn{2}{|c|}{ SEM Totals } & \multicolumn{2}{|c|}{ Overall Total } \\
\hline & & NOG & POG & NOG & POG & NOG & POG \\
\hline Aceraceae & Acer & & & 1 & 0.1 & 1 & 0.1 \\
\hline Arecaceae & & & & 1 & 0.2 & 1 & 0.1 \\
\hline Asteraceae & Cichorioideae type & & & 2 & 0.3 & 2 & 0.2 \\
\hline Asteraceae & Asteroideae LS type & 5 & 0.8 & & & 5 & 0.4 \\
\hline Asteraceae & Asteroideae HS type & 2 & 0.3 & & & 2 & 0.2 \\
\hline Berberidaceae & & & & 1 & 0.2 & 1 & 0.1 \\
\hline Betulaceae & Carpinus & 8 & 1.3 & 8 & 1.3 & 16 & 1.4 \\
\hline Betulaceae & Alnus & 2 & 0.3 & 5 & 0.9 & 7 & 0.6 \\
\hline Betulaceae & Betula & & & 5 & 0.9 & 5 & 0.5 \\
\hline Brassicaceae & & 1 & 0.2 & 2 & 0.3 & 3 & 0.2 \\
\hline Caprifoliaceae & Lonicera & 2 & 0.3 & & & 2 & 0.2 \\
\hline Caryophyllaceae & & & & 1 & 0.2 & 1 & 0.1 \\
\hline Chenopod./Amar. & Cheno-Ams & 3 & 0.5 & 5 & 0.8 & 8 & 0.6 \\
\hline Cupressaceae & & 4 & 0.7 & 15 & 2.5 & 19 & 1.6 \\
\hline Cupressaceae & Funiperus & & & 1 & 0.2 & 1 & 0.1 \\
\hline Ericaceae & Ericaceae & 2 & 0.3 & & & 2 & 0.2 \\
\hline Ericaceae & SEM type 1 & & & 1 & 0.1 & 1 & 0.1 \\
\hline Ericaceae & SEM type 2 & & & 1 & 0.1 & 1 & 0.1 \\
\hline Fabaceae & Acacia & 1 & 0.2 & 1 & 0.1 & 2 & 0.2 \\
\hline Fabaceae & Melilotus & 1 & 0.2 & 2 & 0.3 & 3 & 0.2 \\
\hline Fabaceae & SEM type 2 & & & 2 & 0.3 & 2 & 0.2 \\
\hline Fagaceae & Castanea & 8 & 1.3 & 6 & 0.9 & 14 & 1.1 \\
\hline Fagaceae & Fagus & & & 4 & 0.7 & 4 & 0.4 \\
\hline Fagaceae & Quercus & 2 & 0.3 & 9 & 1.5 & 11 & 0.9 \\
\hline Juglandaceae & fuglans & 1 & 0.2 & & & 1 & 0.1 \\
\hline Liliaceae & Erythronium & & & 1 & 0.2 & 1 & 0.1 \\
\hline Liliaceae & & & & 1 & 0.1 & 1 & 0.1 \\
\hline Malvaceae & & 1 & 0.2 & & & 1 & 0.1 \\
\hline Myrtaceae & LM/SEM total & 110 & 18.4 & 122 & 20.3 & 232 & 19.4 \\
\hline Myrtaceae & SEM type 1 & & & 4 & 0.6 & 4 & 0.3 \\
\hline Myrtaceae & SEM type 2 & & & 85 & 14.2 & 85 & 7.1 \\
\hline Myrtaceae & SEM type 3 & & & 30 & 5.0 & 30 & 2.5 \\
\hline Myrtaceae & SEM type 4 & & & 1 & 0.2 & 1 & 0.1 \\
\hline Myrtaceae & SEM type 5 & & & 2 & 0.3 & 2 & 0.2 \\
\hline Oleaceae & Ligustrum LM/SEM total & 176 & 29.4 & 155 & 25.7 & 331 & 27.6 \\
\hline Oleaceae & Ligustrum SEM type 1 & & & 15 & 2.5 & 15 & 1.3 \\
\hline Oleaceae & Ligustrum SEM type 2 & & & 128 & 21.3 & 129 & 10.8 \\
\hline Oleaceae & Ligustrum SEM type 3 & & & 11 & 1.8 & 11 & 0.9 \\
\hline Oleaceae & Olea & 32 & 5.4 & 39 & 6.5 & 71 & 5.9 \\
\hline Oleaceae & Syringa vulgaris & & & 9 & 1.5 & 9 & 0.7 \\
\hline Pinaceae & Pinus - Diploxylon & 2 & 0.3 & & & 2 & 0.2 \\
\hline Pinaceae & Pinus - Haploxylon & 2 & 0.3 & & & 2 & 0.2 \\
\hline Pinaceae & Pinaceae - Undetermined & 33 & 5.5 & 25 & 4.1 & 58 & 4.8 \\
\hline Plantaginaceae & Plantago LM/SEM total & 2 & 0.3 & 19 & 3.2 & 22 & 1.8 \\
\hline Plantaginaceae & Plantago SEM type 1 & & & 2 & 0.3 & 2 & 0.2 \\
\hline Plantaginaceae & Plantago SEM type 2 & & & 15 & 2.5 & 15 & 1.2 \\
\hline Plantaginaceae & Plantago SEM type 3 & & & 2 & 0.4 & 2 & 0.2 \\
\hline Poaceae & Poaceae & 25 & 4.2 & 19 & 3.2 & 44 & 3.7 \\
\hline Poaceae & Zea mays & & & 1 & 0.2 & 1 & 0.1 \\
\hline Polygonaceae & Rumex & & & 2 & 0.3 & 2 & 0.2 \\
\hline Ranunculaceae & Caltha palustris & & & 3 & 0.4 & 3 & 0.2 \\
\hline Ranunculaceae & & 1 & 0.2 & 1 & 0.2 & 2 & 0.2 \\
\hline Rhamnaceae & & & & 2 & 0.3 & 2 & 0.1 \\
\hline Rutaceae & Citrus & 1 & 0.2 & & & 1 & 0.1 \\
\hline Salicaceae & Populus & 1 & 0.2 & & & 1 & 0.1 \\
\hline Saxifragaceae & Saxifraga & 1 & 0.2 & & & 1 & 0.1 \\
\hline Sparganiaceae & Sparganium & & & 1 & 0.1 & 1 & 0.1 \\
\hline Tiliaceae & Tilia LM/SEM total & 153 & 25.6 & 119 & 19.8 & 272 & 22.7 \\
\hline Tiliaceae & Tilia SEM type 1 & & & 72 & 12.0 & 72 & 6.0 \\
\hline Tiliaceae & Tilia SEM type 2 & & & 8 & 1.4 & 8 & 0.7 \\
\hline Tiliaceae & Tilia SEM type 3 & & & 39 & 6.5 & 39 & 3.3 \\
\hline
\end{tabular}


Table IV. Continued.

\begin{tabular}{|c|c|c|c|c|c|c|c|}
\hline \multirow[b]{2}{*}{ Family } & \multirow[b]{2}{*}{ Taxon or type } & \multicolumn{2}{|c|}{ LM Totals } & \multicolumn{2}{|c|}{ SEM Totals } & \multicolumn{2}{|c|}{ Overall Total } \\
\hline & & NOG & POG & NOG & POG & NOG & POG \\
\hline Ulmaceae & Ulmus & 2 & 0.3 & & & 2 & 0.2 \\
\hline Vitaceae & Parthenocissus & & & 2 & 0.3 & 2 & 0.2 \\
\hline Vitaceae & Vitis & 1 & 0.2 & & & 1 & 0.1 \\
\hline SEM Unknown 1 & & & & 1 & 0.2 & 1 & 0.1 \\
\hline SEM Unknown 2 & & & & 3 & 0.6 & 3 & 0.3 \\
\hline SEM Unknown 3 & & & & 1 & 0.2 & 1 & 0.1 \\
\hline SEM Unknown 4 & & & & 1 & 0.2 & 1 & 0.1 \\
\hline SEM Unknown 5 & & & & 1 & 0.2 & 1 & 0.1 \\
\hline LM Unknown A & & 3 & 0.5 & & & 3 & 0.3 \\
\hline LM Unknown B & & 2 & 0.3 & & & 2 & 0.2 \\
\hline LM Unknown C & & 3 & 0.5 & & & 3 & 0.3 \\
\hline $\begin{array}{r}\text { Degraded (ID } \\
\text { impossible) }\end{array}$ & & 5 & 0.8 & & & 5 & 0.4 \\
\hline Number of taxa & & 33 & & 52 & & 73 & \\
\hline
\end{tabular}

potential for finding or missing a specific pollen type will depend on the amount of the sample examined and the number of pollen grains actually counted (Traverse, 1988).

The results of the present study confirm similar results from an earlier study (Jones and Bryant, 1998) where five drops were extracted from a single processed honey sample. For each drop, a total of 500 pollen grains were counted. Once the counts were finished, a cursory examination of the slide was made to find taxa that were not previously recorded. The results of that study showed that none of the five, 500-grain counts accounted for more than $60 \%$ of the total 130 taxa present in the sample.

Like the results in this study, Jones and Bryant (2004) found that some taxa only occur in one count of a sample while others occur in all the counts.

Table V. Additional pollen types found in the SEM examination.

\begin{tabular}{ll}
\hline Family & \multicolumn{1}{c}{ Taxon or type } \\
\hline Aceraceae & Acer - 2 additional types \\
Apocynaceae & Apocynum \\
Asteraceae & Medium process - 2 types \\
Asteraceae & Cichorioideae - 2 types \\
Caryophyllaceae & Type 2 \\
Fabaceae & Trifolium \\
Hippocastanaceae & Aesculus \\
Lamiaceae & \\
Oleaceae & Fraxinus \\
Parnassiaceae & Parnassia \\
Platanaceae & Platanus \\
Ranunculaceae & Clematis \\
Rhamnaceae & Rhamnus \\
Rutaceae & Zanthoxylum \\
Salviniaceae & Salvinia \\
Scrophulariaceae & Lindernia \\
Typhaceae & Typha angustifolia \\
\hline
\end{tabular}

Furthermore, the number of newly discovered taxa increased as the size of the total pollen count increases.

How long one spends looking for new taxa depends on the amount of funding and the information needed from the study. Obviously, if only the majority of taxa are needed and the top 2 or 3 taxa are the most important, then doing a $1200+$ grain count is not needed. However, if looking for a particular pollen taxon or determining the complete pollen taxa diversity in the sample is warranted, then a 1200 grain count is not sufficient.

Are all pollen counts equal: A question of SEM vs. LM

When the SEM types of Ligustrum, Myrtaceae, and Tilia are combined into their generic and family classification, there was no significant differences in the number of taxa among the counts $(p>0.05$, $\mathrm{F}=0.18, \mathrm{df}=113$ ), between the two LM counts $(p>0.05, F=0.28, d f=51)$, nor between the two SEM counts $(p>0.05, F=0.01, d f=61)$. Even when the SEM taxa were separated, there were no significant differences between the SEM counts $(\mathrm{p}>0.05, \mathrm{~F}=0.06, \mathrm{df}=77)$.

However, a t-test indicated that there was a significant difference in the number of taxa between the SEM and LM $(T=0.05)$ counts. Even so, with only two counts for each technique, more research is needed to determine significant differences between the two techniques.

\section{Conclusion: What to use, LM or SEM?}

Time wise there was little difference between counting a pollen sample using LM or SEM. In 
addition, the sample extraction, processing time, and micrograph production were the same regardless of which microscope was used. One major advantage of LM is convenience and the major advantages of SEM are increased resolution and number of taxa.

When using LM, several things should be remembered. First, there is a possibility of lumping two or more different taxa into one category. How much this effects the overall interpretation of the data depends on the sample and what information is needed from the sample. Second, LM analyses accounted for the least diversity of pollen taxa. Again, the importance of the pollen taxa diversity depends on the type of information needed.

When using SEM, several things should be considered. First, at least two micrographs should be taken of each pollen taxon, one of the whole grain and the second of a close up of the ornamentation of the grain.

Second, the micrographs should be taken at similar magnifications. For example, all pollen grains classified as Tilia should be taken at $1,500-1,800 \mathrm{X}$ and the high magnification of the ornamentation at 5,000X. This standard magnification will change according to the taxon and the family. For example, at 1,500X, a whole Malvaceae pollen grain will not fit on the negative. On the other hand, at 1,500X, Mimosa strigillosa Torr. \& A. Gray is still very small and the whole grain needs to be photographed at 5,000X.

Third, micrographs generated should be housed in a dry, cool area where they can be kept for future use. Digital images also must be cared for and kept in a secure and dry location. When cared for properly, micrographs and negatives should last for at least $50+$ years. How long digital imagery will last depends on technology. At the current rate of new computer technology, common types of storage (CD, DVD) may be obsolete and unreadable in 10-20 years. By keeping the micrographs for years, regardless of their format, there is the chance that an unknown pollen type in the sample will be identified at a later date.

Whenever confronted with the need to decide whether or not to examine a pollen sample using LM, SEM, or both, the sample, the information needed from the sample, and the cost will most likely dictate whether to use LM, SEM, or both. Additional factors for deciding which type of microscope to use are the availability of a SEM, the deadline for the project, and whether precise (genera, species, or sub species levels) or general (genera or family levels) pollen data are needed. For the moment, we suggest that those who are comfortable using LM should continue using LM and those who like to use SEM and have the availability and funding needed for SEM analyses should consider using SEM for statistical pollen counts and identifications.

\section{Acknowledgements}

We appreciate the help of Dr. Matthew Cimino, Curator and Charles O. Wingo, Jr. Herbarium, Salisbury University. We are indebted to Ester F. Wilson, Ashley Johnson, and Bianca Johnson (USDA-ARS, APMRU) for their help with developing and printing all of the LM and SEM micrographs created from this research. We also appreciate Drs. David M. Jarzen (Florida Museum of Natural History) and John G. Jones (Washington State University) for their support and review of the manuscript. We are grateful to the Texas A \& M Microscopy and Imaging Center for use of their SEM. Finally, we appreciate the anonymous reviewers that reviewed this manuscript.

\section{References}

Adam, D. P. \& Mehringer, P. J., Jr. (1975). Modern pollen surface samples: An analysis of subsamples. F. Res. U.S. Geol. Surv., 3, 733-736.

Adams, R. J. \& Morton, J. K. (1972-1979). An atlas of pollen of the trees and shrubs of eastern Canada and the adjacent United States. Waterloo, ONT: Dept Biol. Univ. Waterloo.

Bambara, S. B. \& Leidy, N. A. (1991). An atlas of selected pollen important to honey bees in the eastern United States. Raleigh, NC: N. Carol. St. Beekeep. Assoc.

Bassett, I. J., Crompton, C. W. \& Parmelee, J. A. (1978). An atlas of airborne pollen grains and common fungus spores of Canada. Quebec: Thorne Press Ltd, Can. Dept. Agric. Res. Br. Monogr. 18.

Benedict, J. H., Wolfenbarger, D. A., Bryant, V. M., Jr. \& George, D. M. (1991). Pollens ingested by boll weevils (Coleoptera: Curculionidae) in southern Texas and northeastern Mexico. $\mathcal{F}$. Econ. Entomol., 84, 126-131.

Beug, H.-J. (2004). Leitfaden der Pollenbestimmung für Mitteleuropa und angrenzende Gebiete. München: F. Pfeil.

Blackburn, J. S. \& Ford, J. B. (1993). A study of the foraging behavior of honeybees (Apis mellifera) by the scanning electron microscopic analysis of pollen in honey. Bee Craft, 75, 170-175.

Blackmore, S., Hoen, P. P., Stafford, P. J. \& Punt, W. (Eds). (2003). The Northwest European Pollen Flora. VIII. New York: Elsevier. (http://www.bio.uu.nl/ palaeo/Research2/NEPF/nepf.htm).

Bryant, V. M., Jr., Holloway, R. G., Jones, J. G. \& Carlson, D. L. (1994). Pollen preservation in alkaline soils of the American Southwest. In A. Traverse (Ed.), Sedimentation of organic particles (pp. 47-58). Cambridge, UK: Cambridge Univ. Press.

Bryant, V. M., Jr., Pendleton, M., Murray, R. E., Lingren, P. D. \& Raulston, J. R. (1991). Techniques for studying pollen adhering to nectar-feeding corn earworm (Lepidoptera: Noctuidae) moths using scanning electron microscopy. $\mathcal{F}$. Econ. Entomol., 84, 237-240.

Chen, S.-H. \& Shen, C. (1990). An ultrastructural study of Formosan honey pollen (I). Taiwania, 35, 221-239. 
Del Socorro, A. P. \& Gregg, P. C. (2001). Sunflower (Helianthus annuus $\mathrm{L}$.) pollen as a marker for studies of local movement in Helicoverpa armigera (Hubner) (Lepidoptera: Noctuidae). Aust. F. Entomol., 40, 257-263.

Erdtman, G. (1960). The acetolysis method. Sv. Bot. Tidskr., 54, 561-564.

Grayum, M. H. (1992). Comparative external pollen ultrastructure of the Araceae and putatively related taxa. Lawrence, KS: Allen Press Inc, Monogr. Syst. Bot. Mo. Bot. Gard. 43.

Gregg, P. C. (1993). Pollen as a marker for migration of Helicoverpa armigera and $H$. punctigera (Lepidoptera: Noctuidae) from western Queensland. Aust. f. Ecol., 18, 209-219.

Gregg, P. C., Del Socorro, A. P. \& Rochester, W. A. (2001). Field test of a model of migration of moths (Lepidoptera: Noctuidae) in inland Australia. Aust. F. Ecol., 40, 249-256.

Hendrix, W. H., III. \& Showers, W. B. (1992). Tracing black cutworm and armyworm (Lepidoptera: Noctuidae) northward migration using Pithecellobium and Calliandra pollen. Entomol. Soc. Am., 21, 1092-1096.

Hendrix, W. H., III., Mueller, T. F., Phillips, J. R. \& Davis, O. K. (1987). Pollen as an indicator of long-distance movement of Heliothis zea (Lepidoptera: Noctuidae). Environ. Entomol., 16, 1148-1151.

Herrera, F. \& Urrego, L. E. (1996). Atlas de polen de plantas útiles y cultivadas de la Amazonia colombiana. Santafé de Bogotá: Tropenbos Colombia \& Fund. Erigaie, Estud. Amazonia Colomb. 11.

Jones, G. D. \& Bryant, V. M., Jr. (1998). Are all counts created equal? In V. M. Bryant, Jr \& J. H. Wrenn (Eds), New developments in palynomorph sampling, extraction, and analysis (pp. 115-120). Dallas, TX: AASP Found.

Jones, G. D. \& Bryant, V. M., Jr. (2001). Is one drop enough? In D. K. Goodman \& R. T. Clark (Eds), $9^{\text {th }}$ Int. Palynol. Congr. Proc (pp. 483-487). Dallas, TX: AASP Found.

Jones, G. D. \& Bryant, V. M., Jr. (2004). The use of ETOH for the dilution of honey. Grana, 43, 174-182.

Jones, G. D. \& Coppedge, J. R. (1998). Pollen analyses of the boll weevil exoskeleton. In V. M. Bryant, Jr \& J. H. Wrenn (Eds), New developments in palynomorph sampling, extraction, and analysis (pp. 121-125). Dallas, TX: AASP Found.

Jones, G. D., Bryant, V. M., Jr., Lieux, M. H., Jones, S. D. \& Lingren, P. D. (1995). Pollen of the southeastern United States: with emphasis on melissopalynology and entomopalynology. Dallas, TX: Am. Assoc. Stratigr. Palynol. Found.

Lingren, P. D., Bryant, V. M., Jr., Raulston, J. R., Pendleton, M., Westbrook, J. K. \& Jones, G. D. (1993). Adult feeding host range and migratory activities of corn earworm, cabbage looper, and celery looper (Lepidoptera: Noctuidae) moths as evidenced by attached pollen. F. Econ. Entomol., 86, 1429-1433.

Lingren, P. D., Westbrook, J. K., Bryant, V. M., Jr., Raulston, J. R., Esquivel, J. F. \& Jones, G. D. (1994). Origin of corn earworm (Lepidoptera: Noctuidae) migrants as determined by citrus pollen markers and weather systems. Environ. Entomol., $23,562-570$.

Mabberley, D. J. (1997). The Plant-Book. Cambridge, UK: Cambridge Press.

Mack, R. N. \& Bryant, V. M., Jr. (1974). Modern pollen spectra from the Columbia Basin, Washington. Northw. Sci., 48, 183-194.

Maher, L. (1981). Statistics for microfossil concentration measurements employing samples spiked with marker grains. Rev. Palaeobot. Palynol., 32, 153-191.

Martin, P. S. (1963). The Last 10,000 Years: A Fossil Pollen Record of the American Southwest. Tucson, AZ: Univ. Arizona Press.

Moar, N. T. (1993). Pollen grains of New Zealand dicotyledonous plants. Lincoln, Canterb., N.Z.: Manaaki Whenua Press.
Moore, P. D., Webb, J. A. \& Collinson, M. E. (1991). Pollen Analysis. $2^{\text {nd }}$ Ed. London: Blackwell Sci. Publ.

Nilsson, S., Praglowski, J. \& Nilsson, L. (1977). Atlas of Airborne pollen grains and spores in northern Europe. Natur \& Kultur, Sweden.

Ogden, E. C., Raynor, G. S., Hayes, J. V., Lewis, D. M. \& Haines, J. H. (1974). Manual for sampling airborne pollen. New York: Hafner Press.

Punt, W. (Ed.). (1976). The Northwest European Pollen Flora. I. Amsterdam/Oxford/New York: Elsevier. (http://www.bio.uu.nl/ $\sim$ palaeo/Research2/NEPF/nepf.htm).

Punt, W. \& Clarke, G. C. S. (Eds). (1980). The Northwest European Pollen Flora. II. Amsterdam/Oxford/New York: Elsevier. (http://www.bio.uu.nl/ palaeo/Research2/NEPF/nepf. htm).

Punt, W. \& Clarke, G. C. S. (Eds). (1981). The Northwest European Pollen Flora. III. Amsterdam/Oxford/New York: Elsevier. (http://wwww.bio.uu.nl/ palaeo/Research2/NEPF/nepf.htm).

Punt, W. \& Clarke, G. C. S. (Eds). (1984). The Northwest European Pollen Flora. IV. Amsterdam/Oxford/New York: Elsevier. (http://www.bio.uu.nl/ palaeo/Research2/NEPF/nepf.htm).

Punt, W. \& Clarke, G. C. S. (Eds). (1988). The Northwest European Pollen Flora. V. Amsterdam/Oxford/New York/ Tokyo: Elsevier. (http://www.bio.uu.nl/ palaeo/Research2/ NEPF/nepf.htm).

Punt, W. \& Blackmore, S. (Eds). (1991). The Northwest European Pollen Flora. VI. Amsterdam/Oxford/New York/Tokyo: Elsevier. (http://www.bio.uu.nl/ palaeo/Research2/NEPF/nepf. htm).

Punt, W., Blackmore, S. \& Hoen, P. P. (Eds). (1995). The Northwest European Pollen Flora. VII. Amsterdam/Lausanne/ New York/Oxford/Shannon/Tokyo: Elsevier. (http:// www.bio.uu.nl/ palaeo/Research2/NEPF/nepf.htm).

Qiao, B.-S. (2004). Color atlas of air-borne pollen and plants in China. Beijing: Peking Union Med. Coll. Press.

Reille, M. (1992). Pollen et spores d'Europe et d'Afrique du Nord. Marseille: Lab. Bot. Hist. \& Palynol. URA CNRS/Univ. Marseille III.

Reille, M. (1995). Pollen et spores d'Europe et d'Afrique du Nord. Suppl. 1. Marseille: Lab. Bot. Hist. \& Palynol. URA CNRS/ Univ. Marseille III.

Reille, M. (1998). Pollen et spores d'Europe et d'Afrique du Nord. Suppl. 2. Marseille: Lab. Bot. Hist. \& Palynol. URA CNRS/ Univ. Marseille III.

Reille, M. (1999). Pollen et spores d'Europe et d'Afrique du Nord. Index. Marseille: Lab. Bot. Hist. \& Palynol. URA CNRS Univ./Marseille III.

Ridgeway, J. E. \& Skvarla, J. J. (1969). Scanning electron microscopy as an aid to pollen taxonomy. Ann. Mo. Bot. Gard., 56, 121-124.

Rowley, J. R., Skvarla, J. J. \& Vezey, E. L. (1988). Evaluating the relative contributions of SEM, TEM, and LM to the description of pollen grains. F. Palynol. (India), 23-24, $27-28$.

Skvarla, J. J. \& Larson, D. A. (1965). An electron microscopic study of pollen morphology in the Compositae with special reference to the Ambrosiinae. Grana, 6, 210-269.

Traverse, A. (1988). Palaeopalynology. London: Unwin/Hyman.

Van Laere, O., Lagasse, A. \& Mets, M., de. (1969). Use of the scanning electron microscope for investigating pollen grains isolated from honey samples. f. Apicult. Res., 8, 139-145.

Vezey, E. L. \& Skvarla, J. J. (1990). Computerized feature analysis of exine sculpture patterns. Rev. Palaeobot. Palynol., 64, 187-196.

Vezey, E. L., Skvarla, J. J. \& Vanerpool, S. S. (1991). Characterizing pollen sculpture of three closely-related Capparaceae species using quantitative image analysis of scanning electron 


\section{USDA-ARS Disclaimer}

Mention of trade names or commercial products in this publication is solely for the purpose of providing specific information and does not imply recommendation or endorsement by the U.S. Department of Agriculture. micrographs. In S. Blackmore \& S. J. Barnes (Eds), Pollen and spores: Patterns of diversification (pp. 291-300). Oxford: Clarendon Press, Syst. Assoc. Sp. Vol. 44.

Wei, Z.-X. (Ed.), Wang, H., Gao, L.-M., Zhang, X.-L., Zhou, L.-H. \& Feng, Y.-X. (2003). Pollen flora of seed plants. Kunming: Yunnan Sci. \& Technol. Press. 